\title{
Efetividade e Processo de Conhecimento
}

\author{
Canlos eAllento eAthano de Oliveina
}

Professor Titular de Direito Processual da Faculdade de Direito da UFRGS

Doutor em Direito pela USP

1.

Enquanto ciência cultural, voltado essencialmente à resolução de problemas práticos, o direito sem pre tende à realização. Já o havia as̀sinalado Rudolf von Jhering na grande obra que é o Espirito do Direito Romano (cito da 5. ed. alemã, de 1898, a 1. ed. data de 1858): "O direito existe para se realizar. A realização é a vida e a verdade do direito, é o próprio direito. $O$ que não se traduz em realidade, o que está apenas na lei, apenas no papel, é um direito meramente aparente, nada mais do que palavras vazias. Pelo contrário, o que se realiza como direito é direito, mesmo quando não se encontre na lei e ainda que o povo e a ciência dele não tenham tomado consciência"1. Assim é porque, sobretudo no direito como entidade prática, a determinação da "essência" não comprova a "existência": o direito não é direito sem se manifestar na prática e como prática. Só o cumprimento histórico-concreto, naquele modo de ser que é a vigência e que lhe permite se afirmar como efetiva dimensão da prática humano-social, transforma a juridicidade em direito ${ }^{2}$.

No plano processual, a questão da efetividade ganha corpo a partir da consciência adquirida no início do século XX quanto ao caráter público do processo, considerado um mal social ("sozial Übel", expressão de Frederico, o Grande), um fenômeno doentio, a ser extirpado o mais rápido possível ${ }^{3}$.

No Brasil, o movimento nessa direção também se agiganta - e parece ser esta uma causa nada desprezível — em razão das notórias deficiências da administração da Justiça, agoniada cada vez mais pela intensificação dos litígios, principalmente após o processo de redemocratização iniciado com

1. Rudolf von Jhering, Geist des römischen Rechts auf den verschiedenen Stufen seiner Entwicklung, Teil 2, Abteilung 2, Unveränderter Neudruck der 5. (lezten veränderten) Auflage Leipzig 1898, Aalen, Scientia Verlag, 1968, n²XXXVIII, p. 322. Tomo III, n²3, p. 17, da edição espanhola de 1910, trad. de Enrique Príncepe y Satorres, Madrid, editorial Bailly-Bailliere.

2. Cl., sobre esse tema primordial; A. Castanheira Neves, Metodologia Jurídica — Problemas Fundamentais, Coimbra, Coimbra ed., 1993, p. 25.

3. F. Klein, Zeit-und Geistesströmungen im Prozess, conferência proferida em Dresden em 1901, in Reden, Vorträge, Aufsätze Briefe, Wien, Manz, 1927, vol. L, p. 117-138. 
a promulgação da Constituição de 1988 Dentro desse quadro atuam como reagente a permanência do entulho legislativo auto ritário, as dificuldades de ordem econômica, política e social por que passa a Nação os anseios de grande parte dos cidadãos brasileiros, a recorrer em desespero ao Judiciá rio para solução de conflitos agudos, que normalmente deveriam ser resolvidos pe los demais órgãos do Estado, as contradi ções entre a velha ordem e as idéia neoliberais, redobradas pelo fenômeno da globalização, pregando a redução do aparelho estatal, mesmo a preço de afrontas ao direito adquirido de significativas parcelas da população. Certamente, tudo isso colabora para o descrédito da Jurisdição e acar reta a demora excessiva do processo fazendo com que se forme um caldo de cul tura propício a que, no limite, se tenda a ver a efetividade não como um meio, mas como um fim em si mesmo.

O paroxismo chegou a tal ponto que para alguns espíritos mais práticos tudo se resume na solução rápida, expedita, fulminante às vezes do próprio valor Justiça. Essa conseqüência, porém, não vem por acaso e parece se iniciar com a condição do homem moderno, posto perante um mundo de faticidade empírica e de causalidade, e por isso axiologicamente neutro. Nessa linha de entendimento, segundo Max Weber o "de sencantamento do mundo", o racionalismo define o desenvolvimento histórico do Oci dente, por meio da substituição dos meios

mágicos e extra-racionais pelo método e pelo cálculo racional em todos os setores da vida social ${ }^{4}$. Desse modo, a perspectiva "teleológica", entrosada com uma ordem valorativa, vai sendo substituída por uma visão "mecanicista" ligada a um "esquema causal". Os fins deixam de ser a expressão teleológica de uma ordem onto-axiológica - na qual o valor reina soberano- para se converterem em simples manifestações de pretensões subjetivas, acabando a ação por ser avaliada apenas pela sua eficiência quanto aos objetivos e sua eficácia nos efeitos. Na condição pós-moderna o resultado pode ser assustador: os padrões de avaliação, as categorias da ação e do comportamento em geral (pessoal ou institucional) deixaram de se pautar por valores como o bem, o justo, a validade (axiológica material), para serem as do útil, da oportunidade, da eficiência, da eficácia. $\mathrm{Na}$ base de tudo entroniza-se a "ideologia tecnocrática"; a legitimação dáse pela performance, sendo o lugar da ética usurpado pelo conhecimento das relações entre os elementos do sistema e a técnica da sua manipulação eficiente: uma coisa é boa se ela se mostra adequada ao fim perseguido e este fim é ele próprio desejável por produzir resultados que satisfaçam a uma finalidade mais geral ${ }^{5}$.

A questão que se coloca em semethante contexto é se realmente se mostra desejável esse tipo de efetividade, indiferente à justiça, que conduz a uma negativa contraposição entre utilitarismo e justiça na

4. Max Weber, Economia y sociedad (esbozo de sociología comprensiva), ed. preparada por Johannes Wincklemann, trad. de José Medina Echavarría, Juan Roura Parella, Eugenio Ímaz, Eduardo García Máynez e José Ferrater Mora, México, Fondo de Cultura Medina Echavarría, Juan Roura Parella, Eugen

5. J.F. Lyotard, A condição pós-moderna, trad. port., p. 322 ss e $87 \mathrm{ss,} \mathrm{passim,} \mathrm{apud} \mathrm{Castanheira} \mathrm{Neves,} \mathrm{ob.} \mathrm{cit.,} \mathrm{p.} \mathrm{44.} \mathrm{Castanheira}$ Neves, ob. cit., p. 60 .

Revista da Faculdade de Direito da UFRGS, v. 16, 1999 medida em que a relativiza em função da performance, a transformar o juiz em burocrata, assimilando as funções executiva e judicial.

A nosso entender a efetividade só se revela virtuosa se não colocar no limbo outros valores importantes do processo, a começar pelo da justiça, mas não só por este. Justiça no processo significa exercício da função jurisdicional de conformidade com os valores e princípios normativos conformadores do processo justo em determinada sociedade (imparcialidade e independência do órgão judicial, contraditório, ampla defesa, igualdade formal e material das partes, juiz natural, motivação, publicidade das audiências, término do processo em prazo razoável, direito à prova). Por isso, a racionalidade do direito processual não há de ser a racionalidade tecnológica-estratégica, mas a orientada por uma validade normativa que a fundamente e ao mesmo tempo fundamentada pelo discurso racional do juízo, de modo a que a sociedade possa controlar tanto a correção material quanto a concordância dogmática da decisão ${ }^{6}$. Não desconheço, é claro, que o próprio valor justiça, espelhando a finalidade jurídica do processo, encontra-se intimamente relacionado com a atuação concreta e eficiente do direito material, entendido em sentido amplo como todas as situações subjetivas de vantagem conferidas pela ordem jurídica aos sujeitos de direito. Por isso mesmo, o acesso à justiça, elevado ao patamar de garantia constitucional na tradição jurídica brasileira, deve certamente compre- ender uma proteção juridicamente eficaz e temporalmente adequada. $O$ que ponho em questão é a eficiência como fim, sem temperamentos, como meta absoluta, desatenta a outros valores e princípios normativos. O ponto é importante porque esses ditames axiológicos, além de se afinarem mais com a visão de um Estado democrático e participativo, poderão não só contribuir para a justiça da decisão como até para a própria efetividade.

Nessa perspectiva, dois aspectos de vem ser destacados: a necessidade de um maior informalismo e a acentuação do princípio fundamental da cooperação entre o órgão judicial e as partes. Em tal concepção estão implicados, como se verá, valores indispensáveis para uma visão atualizada do fenômeno processual.

2. A história do direito processual, apesar dos naturais e inevitáveis retrocessos, marchas e contramarchas, aponta a um ciclo ascendente de evolução, que chamaria de helicoidal. Esse ciclo se inicia em épocas recuadas no tempo com um formalismo de caráter simbólico e religioso. Prossegue com o formalismo excessivo e exagerado da Idade Média, até atingir uma progressiva humanização, contemporânea ao racionalismo e ao iluminismo, com a lenta aproximação do juiz à realização da prova e ao contato direto com as partes. E culmina com o juiz ativista dos tempos que correm, idealmente em busca de permanente diálogo e colaboração com as partes, época em que se esgota o primado da forma e se con-

6. Cf. Esser, as differentes dimensōes da racionalidade juridica se manifestam no controle da correção material (Richtigkeitskontrolle), referido ao problema concreto trazido à consideração do órgão judicial, e o controle da concordância dogmática

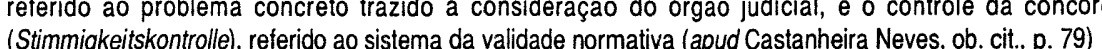


cede maior atenção aos fins sociais e políticos do processo?

O direito brasileiro, embora tenha acompanhado essa linha de evolução, às vezes ao preço de alguma defasagem temporal, até agora não se preocupou em flexibilizar a conformação material do processo em homenagem ao princípio dispositivo - princípio esse que constitui, sem a menor sombra de dúvida, o maior limite formal à atuação do órgão judicial. $\mathrm{O}$ CPC de 1973 revela-se a esse respeito de uma rigidez extraordinária, numa visão mais afeiçoada com o espírito das legislações do século XIX: feita a citação, é defeso ao autor modificar o pedido ou a causa de pedir sem o consentimento do réu (art. 264, 1ª . parte); depois do saneamento do processo em nenhuma hipótese tal alteração será permitida (art. 264, $2^{\mathrm{a}}$. parte).

Decerto razões de política judiciária, em que ganha destaque a imprescindível imparcialidade do órgão judicial, tornam oportuno o seu total afastamento tanto do pedido quanto da indicação da causa petendi. Todavia, parece-me de toda conveniência coordenar esse rigorismo formal com o princípio da economia processual, emprestando assim maior agilidade ao processo, em busca da boa efetividade.

Lembro a experiência alemã, ao permitir a modificação da demanda, independente de anuência do adversário, se entendido pelo órgão judicial estar presente o requisito da "utilidade" para a causa (Sachdienlichkeit: § 263, com a redação da Novela de 1933). Para a jurisprudência constituem elementos decisivos para a aplicação desse conceito o interesse público no rápido desenvolvimento do processo e as exigências de economia do juízo ${ }^{8}$.

Na mesma esteira, o $§ 235,3$, da Ordenança Processual austríaca autoriza o juiz a permitir a modificação da demanda se não conduz ao "retardamento relevante" e ao "agravamento" do desenvolvimento do processo 9 .

A esse modo de ver o problema não ficou alheia a Ordenança Processual de Berna, cujo $\S 94$ admite a alteração da ação ou da reconvenção, sem o consentimento da parte contrária, se apoiada em causa de pedir semelhante à anterior pretensão ou conexa com a exercida, entendendo o órgão judicial não decorrer daí considerável agravamento ou demora no processamento da causa ${ }^{10}$.

Nessa mesma perspectiva, revela-se interessante e original a solução preconizada na ampla e profunda reforma introduzida no processo civil português ocorrida em

7. Sobre o tema, amplo desenvolvimento em C. A. Alvaro de Oliveira, Do formalismo no processo civil, São Paulo, Saraiva, 1997, p. 11-60, passim.

8. Como informa Othmar Jauernig, Zivilprozessrecht, 21. ed., München, Beck, 1985, §41, III, p. 150, os tribunais alemães levam em conta a possibilidade de a modificação evitar um novo processo, mas a consideram inadmissível quando dela resulta a apreciação de relaçōes juridicas totalmente distintas entre as mesmas partes ou maior dificuldade de defesa do réu.

9. A respeito, Corrado Ferri, Struttura del processo e modificazione della domanda, Padova, Cedam, 1975, p. 104-6.

10. Alois Troller, Von den Grundlagen des zivilprozessualen Formalismus, Basel, Helbing \& Lichtenhahn, 1945, § 7, p. 94
1995 e $1996^{11}$, em que se faculta, mesmo sem concordância da outra parte (CPC por tuguês, art. 273, incisos 1 a 6): a) a alteração ou ampliação da causa de pedir na réplica, se o processo a admitir, a não ser que a alteração ou a ampliação seja conse qüência de confissão feita pelo réu e aceita pelo autor; b) a alteração ou ampliação do pedido na réplica, podendo, além disso, o autor, em qualquer altura, reduzir o pedido e ampliá-lo até o encerramento da discussão em $1^{\mathrm{O}}$ grau de jurisdição se a ampliação consistir em desenvolvimento ou conseqü ência do pedido primitivo; c) a ampliação ou alteração do pedido de aplicação de san ção pecuniária compulsória no caso de obri gações de prestação de fato infungíveis̀, ao abrigo do disposto no art. 829, I, do Código Civil, respeitados os termos do art. 273, 2 do CPC; d) ao autor requerer nas ações de indenização fundadas em responsabilidade civil, até o encerramento da audiência de discussão e julgamento em $1 \stackrel{o}{\text { grau de juris }}$ dição, a condenação do réu em forma de renda vitalícia ou temporária (art. 567 do Código Civil), mesmo que inicialmente te nha pedido a condenação daquele em quantia certa; e) a modificação simultânea do pedido e da causa de pedir, desde que tal não implique convolação para relação jurídica diversa da controvertida.

11. Essa reforma, cuja importância é indesmentível, pelo que representa de modernidade e de adequação às determinantes axiológicas do processo atual, decorre da protunda alteração determinada pelos decretos-lei 329-A, de 12 de dezembro de 1995, e 180, de 25 de setembro de 1996. Visão ampla e abrangente a respeito em Miguel Teixeira de Sousa, Estudos sobre o novo processo civil, 2. ed., Lisboa, Lex, 1997, passim.

12. Especificamente sobre o ponto, José Lebre de Freitas, Introdução ao Processo Civil (conceito e princípios gerais à luz do Código

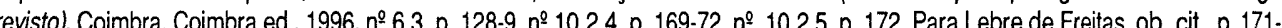
2 a ma a nova causa de pedir coincidam com fatos que neir reconvencional ou fundem exceşōes deduzidas, mas tambem quando, pelo menos, o novo pedido se reponte a uma relaçăo material dependente ou sucedânea da

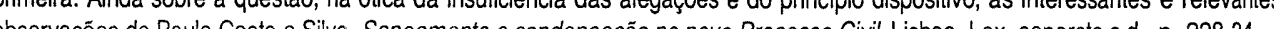


Ainda na seara da contraposição formalismo versus informalismo, registro uma da mais preocupantes tendências atuais do direito brasileiro: o formalismo excessivo, exagerado, na admissão dos recursos. Um dos casos típicos é a formação do instrumento de agravo, agora posta como encargo da parte (art. 525, I, do CPC). Assim, se um dos documentos ali relacionados não integra o instrumento, os tribunais brasileiros quase que invariavelmente, mesmo na instância ordinária, não mandam suprir a falta e se negam a conhecer do recurso por inadmissível. Às vezes o formalismo chega a se alçar aos píncaros dos exageros do processo romano-canônico: o recurso deixa de ser conhecido porque a tempestividade foi demonstrada com cópia do Diário da Justiça e não com certidão do cartório judicial ou porque não se apresentou certidão de inteiro teor da decisão agravada, conquanto reproduzida integralmente no órgão oficial, que o diligente recorrente cuidou de juntar aos autos! Os resultados dessa forma obtidos podem impressionar do ponto de vista meramente estatístico, mas com certeza não servem à justiça. A efetividade que sustenta essa maneira de ver o problema é a efetividade ruim, preocupada tão somente com a performance.

Todavia, o processo não foi feito para punir desatenções, e sim para fazer justiça, desiderato essencial muitas vezes afastado com o não-conhecimento do agravo em questão de extrema importância para a boa solução do litígio. $O$ mero defeito formal não pode

13. Cf., por todos, Alois Troller, Linfluence de la Constitution Fédérale de la Confédération Suisse sur les droits de parties devant les tribunaux cantonaux en matière de procédure civile, in Cappelletti e Tallon (organizadores), Fundamental guarentees of the parties in civil litigation, Milano, Giuffrè, 1973, p. 637. Indicação bibliográfica mais ampla em C. A. Alvaro de Oliveira, Do formalismo, cit., p. 193-5.

Revista da Faculdade de Direito da UFRGS, v. 16, 1999 urisdição. Inexistirá verdadeira efetividade e assim se entende a efetividade com justiça - na ausência de colaboração entre o órgão judicial e as partes, porque este é realmente o único caminho para serem solucionadas as inúmeras dificuldades decorrentes da angustiante tarefa de prestar jurisdição de forma democrática. O ponto é assaz significativo, na medida em que o Judiciário só pode se legitimar e ser prestigiado - como é altamente desejável pela importância de seu papel institucional - quando se torne real e efetiva essa cooperação, mormente porque o advogado é a interface do Judiciário com a sociedade civil. Colaboração aqui significa, da perspectiva do órgão judicial, ouvir as partes, seus representantes ou mandatários judiciais, convidando-os a fornecer esclarecimentos sobre a matéria de fato ou de direito, assim como para suprir as faltas acaso existentes.

É com esse espírito, com essa inclinação por fazer justiça, que a jurisprudência da mais alta corte da Suíça, o Bundes Gericht, tem considerado excesso de formalismo e qualificado como denegação de justiça as hipóteses, entre outras, de não-recebimento de recurso interposto por pessoa sem procuração escrita, de manifestação recursal desacompanhada de cópia certificada da decisão impugnada ou posta no correio no último dia do prazo e recebida pela autoridade judiciária a destempo. Tudo isso com base no art. 4ํ da Constituição Federal suí ça, cuja única preocupação é assegurar a igualdade de todos perante a lei ${ }^{13}$ !
Registro de passagem inexistir no re gime atual do Código de 1973 qualquer re gra a impor ao relator do agravo o indeferimento liminar na falta de peças es senciais, pois vedado não está o suprimento da falta, seja no art. 527, caput, seja no art. 557. A sanação aqui defendida encon tra-se, aliás, em sintonia com o valor relati vo das formas legais, assentado no sistema das nulidades adotado entre nós ${ }^{14}$. De qual quer modo, entendo de bom alvitre sugerir à consideração dos doutos, para possível inclusão na próxima reforma do processo civil, a criação de regra semelhante à con tida no simples e eficiente art. 742,4 , do CPC português: "Se faltar algum elemento que o tribunal superior considere necessá rio ao julgamento do recurso, requisitá-loá por simples ofício."

3. As últimas considerações introdu ziram na discussão o valor capital da coo peração, sobre o qual penso ser conveniente centrar agora o foco da análise.

O iudicium ou ordo iudiciarius, vigo rante até o século XVII, era fartamente influenciado pelas idéias expressas na retórica e na tópica aristotélica, concebiEnciclopedia del Diritto, XXXVI(1987):101-118. do e pensado como ars dissedendi e ars opponendi et respondendi tudo com vistas a resolver o problema, que ocupava o centro da discussão. Na lógica do provável, pressuposta por tal concepção, a investigação da verdade não se apresentava como o resultado de uma razão individual, mas do esforço combinado das partes, revelando-se implícita uma atitude de tolerância em relação aos "pontos de vista" do outro e o caráter de sociabilidade do saber. Como o iudicium era imposto pela prática judiciária à margem da autoridade estatal, decorrente apenas da elaboração doutrinária, sem qualquer assento em regra escrita, reclamava de maneira intrínseca uma paritária e recíproca regulamentação do diálogo judiciário ${ }^{15}$. O ponto de importância para o nosso tema é essa "ordem isonômica", que visava a garantir a igualdade entre governantes e governados, entre o juiz e as partes e entre as próprias partes $^{16}$.

A mudança de perspectiva, introduzida pela lógica de Petrus Ramus $(1515-1572)^{17}$, já antecipa uma alteração de rumo que busca incorporar ao direito

14. Atento a esses valores essenciais, Galeno Lacerda já na sua tese de cátedra, nos idos de 1953, o hoje clássico Despacho Saneador, p. 112, afirmava, com inteira razão, que "será sempre sanável a falta de representação das partes por profissional habilitado." Dando exata interpretação ao art. 13 do CPC, O STJ, Corte Especial, un., (RSTJ, 68/383), julgou que "A falta de instrumento de mandato constitui defeito sanável nas instâncias ordinárias, aplicando-se, para o fim de regularização da representaçao postulatơria, o disposto no art. 13 do CPC. No mesmo senlido: STJ, 2a. Seção, Com Ire 3. Turma, RESp 115.678-MT, rel. Ministro Nilson Naves, v. u., DJU de 23.6.97, p. 29.128.

15. A respeito, a obra fundamental de Alessandro Giuliani, II concetto de prova (contributo alla logica giuridica), Milano, Giuffrè, 1961, p. 145-6, passim. Ver, ainda, do mesmo autor, Logica del diritto (teoria dell'argomentazione), in Enciclopedia del Diritto, XXV(1975)13:34. Instigante e por demais reveladora a admirável síntese de Nicola Picardi, Processo Civile (dir. moderno), in

16. Picardi, Processo Civile (dir. moderno), cit., p. 116.

17. Revela-se significativo o título da tese de graduação de Pierre de la Ramée: "Tudo que Aristotéles ensinou é falso" (1536). A crítica à velha lógica atingiu sua plenitude com a publicação da obra Aristotelicae Animadversiones (1543). A influência de sua lógica pode ser aferida pelo fato de que, dois anos antes da morte de Ramus, Milton tivesse publicado um pequeno tratado a respeito: Artis logicae Plenior Institutio ad Petri Rami Methodum concinnata. 

senta um caráter "assimétrico" na medida os métodos próprios da ciência da natureza, um pensamento orientado pelo sistema, em busca de uma verdade menos provável, com aspirações de certeza, a im plicar a passagem do iudicium ao processus. Tudo isso se potencializa, a partir do século XVII, com a estatização do processo, com a apropriação do ordo iudiciarius pelo soberano, pelo príncipe, que passa a reivindicar o monopólio da legislação em matéria processual, tendência incrementada depois pelas idéias do iluminismo e pelo verdadeiro terremoto produzido pela Revolução francesa. ${ }^{18}$ Perde-se, assim, a dimensão retórica do processo. Mais do que isso, a intromissão estatal do processo judicial passa a se re fletir nos poderes do juiz. O órgão judicial assume uma posição dominante e superior em relação às partes. O novo ordo apreem que baseado na autoridade, na hierarquia e na lógica burocrática ${ }^{19}$.

A partir dos anos cinqüenta do século XX, com a renovação dos estudos de lógica jurídica ${ }^{20}$ e a ênfase emprestada ao sentido problemático do direito, resgatase em certa medida a dimensão retórica e dialética do processo. Tal fenômeno ocorreu exatamente quando - já prenuncian-

do o pós-modernismo - mais agudos e prementes se tornavam os conflitos de va lores e mais imprecisos e elásticos os conceitos $^{21}$.

Recupera-se, assim, o valor essencial do diálogo judicial na formação do juízo fruto da cooperação das partes com o órgão judicial e deste com as partes, segundo as regras formais do processo. Essa conseqüência, por outro lado, reforça-se pela percepção de uma democracia mais participativa, com um conseqüente exercí cio mais ativo da cidadania, inclusive de natureza processual. Ora, a idéia de coope ração há de implicar, sim, um juiz ativo colocado no centro da controvérsia, mas também a recuperação do caráter isonômico do processo, com a participação ativa das partes. O diálogo assim estimulado substitui com vantagem a oposição e o confron to, dando azo ao concurso das atividade dos sujeitos processuais, com ampla colaboração tanto na pesquisa dos fatos quanto na valorização da causa. Esse objetivo só pode ser alcançado pelo fortalecimento dos poderes das partes, por sua participação mais ativa e leal no processo de formação da decisão, dentro de uma visão não auto ritária do papel do juiz e mais contemporânea quanto à divisão do trabalho entre o

18. Picardi, Processo Civile (dir. moderno), cit, p. 110-117.

19. Picardi, Processo Civile (dir. moderno), cit, p. 117. Miguel Teixeira de Sousa, Estudos, cit., p. 87-8.

20. Assim a obra de Theodor Viehweg, Topik und Jurisprudenz (Ein Beitrag zur rechtswissenchaftlichen Grundgenforschung), cuja 1. edição data de 1953, de Giuliani, acima citada, e de Chaïm Perelman (v.g., Tratado da Argumentaçăo (a nova retórica), en colaboraçăo com Lucie Olberechts-Tyteca, 1958, edição brasileira na trad. de Maria Ermantina Galvão G. Pereira, São Paulo, Martins Fontes, 1996).

21. Por isso, já em 1973 observava Fritz Baur, Les garanties fondamentales des parties dans le procès civil en République Fédérale d'Allemagne, in Fundamental Guarantees, cit., p. 3-30, esp. p. 19, que "um sobrevôo da jurisprudência dos tribunais alemães, em

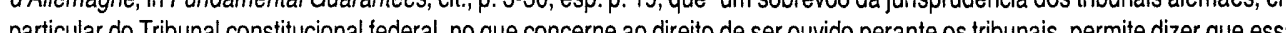
particular do Tibunal con (a) órgão judicial e as partes ${ }^{22}$. Aceitas essas premissas axiológicas, cumpre afastar a incapacidade para o diálogo estimulada pela atual conformação do processo judicial brásileiro, assentado em outros valores ${ }^{23}$. Por todas essas razões, é da maior conveniência restabelecer o ordo isonômico, propósito que parece ser de magna importância para a efetividade virtuosa no processo de conhecimento.

Claro está que esse desiderato, além da necessária e indispensável predisposição cultural, só pode ser atingido mediante reformas de cunho legislativo. Sem preocupação de esgotar a matéria, alinho rapidamente algumas sugestões què me parecem significativas

Antes de mais nada, impõe-se a adoção do princípio da cooperação, como pedra angular e exponencial do processo civille.

De bom alvitre seria também, dentro dessa linha de orientação, eliminar os reflexos gravosos, de ordem processual, acarretados pelo não pagamento de custas ou de taxa judiciária. $O$ processo não deve ser extinto nem o recurso julgado deserto pelo descumprimento desses encargos, de- v'endo a parte sofrer apenas uma sanção estritamente pecuniária, traduzida pelo agravamento, eventual e substancial, dos montantes devidos 25 .

estabelecimento, como princípio geral do processo, do princípio da adequação formal, facultando ao juiz, obtido o acordo das partes, e sempre que a tramitação processual prevista na lei não se adapte perfeitamente às exigências da demanda aforada, a possibilidade de amoldar o procedimento à especificidade da causa, por meio da prática de atos que melhor se pres. tem à apuração da verdade e acerto da decisão, prescindindo dos que se revelem inidôneos para o fim do processo ${ }^{26}$.

Veto ao órgão judicial para decidir questões de fato ou de direito, mesmo que de conhecimento ex officio, sem prévio pronunciamento das partes a respeito, de modo a emprestar outra dimensão ao contraditório, afeiçoando-o a uma visão cooperativista do processo. Hoje, esse resultado só é alcançável no direito brasileiro por via interpretativa ${ }^{27}$.

Extinção dos chamados "privilégios processuais" dos entes estatais nos litígios em que estejam envolvidos. Esse aspecto
22. A respeito dessas idéias, C. A. Alvaro de Oliveira, Do formalismo, cit., p. 133-140, passim.

23. Como bem pondera Hans-Georg Gadamer, La incapacidad para el diálogo (1971), in Verdad y Metodo, vol. Il, 2. ed., trad. de Manuel Olasagasti, Salamanca, Sígueme, 1994, p. 203-210, embora a capacidade para o diálogo seja um atributo natural do homem, pois a linguagem só se dá no diálogo, muitas vezes não se quer ouvir o outro, ou se ouve mal.

24. No CPC português, a cooperação intersubjetiva encontra-se expressamente regulada no art. 266, mas tem inflexão direta em diversos dispositivos. Ver, a propósito, Miguel Teixeira de Sousa Estudos, cit., p. 62-69.

25. Dentro desse espirito, assim regulam a matéria em Portugal os arts. 13 e 14 do mencionado decreto-lei 329-A95.

26. Assim preceitua o art. 265-A do CPC português: "Quando a tramitação processual prevista na lei não se adequar às especificidades da causa, deve o juiz oficiosamente, ouvidas as partes, determinar a prática dos atos que melhor se ajustem ao fim do processo, bem como as necessárias adaptaçōes."

27. Sobre essa nova perspectiva do princíipio, cf. C. A. Alvaro de Oliveira, A garantia do contraditório, in Garantias Constitucionais do Processo Civil, coordenação de José Rogério Cruz e Tucci, São Paulo, RT, 1999, p. 132-150. 
mostra-se particularmente relevante dian te da recente duplicação do prazo de deca dência para o ajuizamento de ação rescisória de sentença pelo Ministério Público, a União, os Estados, o Distrito Federal, os Municípios, suas autarquias e fundações ${ }^{28}$, em flagrante ofensa ao princípio da igual dade

Intensificação do dever de boa fé processual, sancionando-se como litigante de má fé a parte que, não apenas com dolo, ma com negligência grave, deduza pretensão manifestamente infundada, altere, por ação ou omissão, a verdade dos fatos relevantes da causa, pratique omissão indesculpável do dever de cooperação ou faça uso reprováve dos instrumentos processuais.

Também nesse contexto impõe-se dever de recíproca correção entre o juiz os diversos intervenientes ou sujeitos pro cessuais. Como necessário reflexo dessa correção, ao ângulo visual do órgão judi cial, podem ser citados, a título de exemplo, os deveres de pontualidade no início dos atos e audiências realizados em juízo ${ }^{29}$, o de não motivar falsamente a decisão judicial e o de apreciar integralmente os fundamentos relevantes dos arrazoados das partes.

Por outro lado, o sistema jurídico brasileiro tem se inclinado por uma cres

cente supervalorização do trabalho do perito oficial nomeado pelo diretor do processo, reduzindo dessa forma, com intensidade cada vez maior, a importância dos laudos apresentados pelos assistentes técnicos das partes. Essa conseqüência torna-se ainda mais grave pelo notável incremento verificado no número de demandas, a tornar mais rarefeito o exame das conclusões da perícia peloljuiz. Não bastasse essa circunstância, a reforma introduzida pela Lei $\mathrm{n}^{\circ} \mathbf{8 . 4 5 5}$, de 24.8.1992 no instituto da perícia só veio a estimular, na contramão da história, esses inconvenientes, por ter reduzido de maneira considerável o papel até então desempenhado pelos assistentes técnicos, que, de verdadeiros auxiliares do juízo, passaram à condição de simples informantes e pareceristas pagos pelas partes. Semelhante conclusão encontra-se alicerçada na nova redação do $\S 2^{\circ}$, $2^{\text {a }}$. parte, do art. 422 , - a dispensar os assistentes técnicos de prestarem compromisso de cumprir conscienciosamente o encargo que lhes for cometido-, do art. 423 , - a determinar que os assistentes técnicos não podem mais ser recusados por impedimento ou suspeição-, do art. 424, caput, a não mais prever a possibilidade de substituição do assistente técnico pelo juiz —, e ainda na revogação dos arts. 430 e 431, que impunham prévia conferência

\footnotetext{
28. Medida Provisória 1.774-20, de 14.12.1998, art. $5^{2}$.

29. OCPC português, art. 456, 2, alargou com boas razōes o âmbito da má fé processual aos casos de negligência grave. No mesmo estatuto, o dever de colaboração do órgão judicial com as partes foi sublinhado nos arts. 266, 2, 266, 4, 508, 1, "b", 508-A, 1, "c", $690,4, e 701$, 1. No Brasil, o anteprojeto de lei n² 13, em tramitação no Congresso Nacional, năo só propõe a alteraçăa do caput art. 14 do CPC, como também a inclusão de novo inciso: "Artigo 14. São deveres das partes, de seus procuradores e de todos aqueles que de qualquer forma participam do processo: $\vee$ — cumprir com exatidão os provimentos mandamentais e năo criar embaraços à efetivaçăo de provimentos judiciais, antecipatórios ou finais." A declarada intenção da reforma legislativa, como se lê na exposição de motivos, é reforçar a ética no processo, o que só merece aplausos. Na perspectiva do texto, poder-se-ia ainda afirmar que, além disso, a inovação intensifica o dever de cooperação.
}

Revista da Faculdade de Direito da UFRGS, v. 16, 1999 entre o perito e os assistentes técnicos e a elaboração de laudo em separado somente

A nova realidade aqui retratada está a determinar reflexão mais acurada sobre o modus operandi da perícia no sistema jurídico brasileiro. Tudo aconselha - nomeadamente nos parâmetros de uma desejável e inafastável visão cooperativa do processo - a prévia audição das partes a respeito da escolha do expert, facultando-se-lhes sugerir quem deve realizar a diligência, não podendo o juiz se eximir de nomear o perito por elas indicado de comum acordo, salvo se tiver fundadas razões para questionar sua idoneidade ou competência ${ }^{30}$. Com essa providência em muito ganharia a busca da verdade dentro do processo, mormente nas espécies de alta complexidade técnica ou científica, ainda mais que a prática do foro demonstra que, no presente estágio de desenvolvimento da sociedade brasileira, seria de todo conve. niente desfrutasse o perito da confiança não só do órgão judicial mas também dos litigantes.

4. Penso, porém, que as medidas pontuais sugeridas e outras de caráter puramenem caso de divergência.

te legislativo não se mostrarão suficientes para resolver de todo a crise profunda da administração da Justiça entre nós. Aliás, o problema apresenta perfil mundial, pois em todos os países verifica-se aumento desme surado do número de demandas, intensificação dos litígios e escassez de recursos e material humano para diminuir ou eliminar a defasagem entre o número de juízes e de causas ${ }^{31}$.

Paralelamente, o tempo tornou-se em nossos dias um dos parâmetros fundamentais da Justiça moderna, em face da mudança de natureza qualitativa na natureza dos litígios, na maior parte surgidos em virtude da massificação da economia, abrangendo um número enorme de pessoas de poucos ou médios recursos ${ }^{32}$. A tudo isso se acrescenta a extraordinária velocidade do mundo atual, decorrente da revolução informática, a exigir um novo paradigma de Justiça, certamente diverso do modelo iluminista que inaugurou a modernidade.

Esse novo paradigma há de ser criado a partir da experiência brasileira, das suas dificuldades e das suas potencialidades, por meio de uma discussão aber-

30. Assim o art. 568, 2, do CPC português. A critica ao atual sistema brasileiro encontra-se em C. A. Alvaro de Oliveira, Problemas atuais da livre apreciação da prova, in Prova Civel, coordenação de C. A. Alvaro de Oliveira, Rio de Janeiro, Forense, 1999, p. 47. 60.

31. Roger Perrot, O processo civil francês na véspera do século XXI, trad. de J. C. Barbosa Moreira, Revista Forense, 342(abril-maiojunho de 1998):161-168, esp. p. 163, mostra bem como em nossos dias o tempo tornou-se um dos parâmetros da Justiça moderna e como estáo os tribunais franceses entulhados de contencioso sempre mais abundante, sem que se possa pensar no aumento do número de juizes, seja por impossibilidades de ordem orçamentária, seja por inexistência de material humano, pois um aumento rápido importaria baixar perigosamente a qualidade do recrutamento.

32. Cf. Roger Perrot, ob. e loc. cits., "Quando se litigava, como no começo do século, sobre a definiçăo de sucessões, sobre o direito de propriedade, sobre servidóes ou usurfutos, a lentidāo dos processos era talvez algo de irritante, mas a gente acabava por se

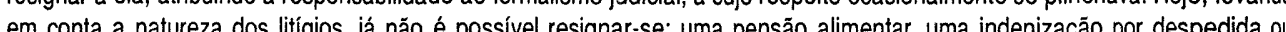
desinada a ressarir um denor Justiça moderna." 
ta com toda a sociedade civil, com participação ativa das sociedades represen-

tativas dos advogados, dos juízes, dos promotores, dos especialistas, professores e juristas e dos operadores do direito em geral. A meu ver, uma das questões fundamentais de tal pauta deverá ser constituída da necessidade de ser preservado o Poder Judiciário para a solução das controvérsias realmente importantes e, do mesmo passo, estimuladas soluções à margem do sistema es tatal, de modo a desafogá-lo e permitir o exercício adequado de suas altas funções O tema, contudo, pela sua complexida de e extensão, não comporta exame nes. ta sede.

\section{Bibliografia}

Alvaro de Oliveira, C. A. Do formalismo no proces so civil, São Paulo, Saraiva, 1997.

A garantia do contraditório, in Garantias Constitucionais do Processo Civil, co ordenação de José Rogério Cruz e Tucci, São Paulo, RT, 1999, p. 132-150.

. Problemas atuais da livre apreciação da prova, in Prova Cível, coordenação de C. A. Alvaro de Oliveira, Rio de Janeiro, Fo rense, 1999 , p. 47-60.

Baur, Fritz. Les garanties fondamentales des parties dans le procès civil en République Fédérale d'Allemagne, in Cappelletti e Tallon (organizadores), Fundamental guarentees of the parties in civil litigation, Milano, Giuffrè, 1973

Castanheira Neves, A. Metodologia Jurídica - Problemas Fundamentais, Coimbra, Coimbra ed. 1993

Costa e Silva, Paula. Saneamento e condensação no novo Processo Civil, Lisboa, Lex, separata s.d.

Revista da Faculdade de Direito da UFRGS, v. 16, 1999
Ferri, Corrado. Struttura del processo e modificazione della domanda, Padova, Cedam, 1975.

Gadamer, Hans-Georg. La incapacidad para el diálogo (1971), in Verdad y Metodo, vol. II, 2. ed., trad. de Manuel Olasagasti, Salamanca, Sígueme, 1994.

Giuliani, Alessandro. Il concetto de prova (contributo alla logica giuridica), Milano, Giuffrè, 1961.

Logica del diritto (teoria dell'argomentazione), in Enciclopedia del Diritto, XXV(1975) 13:34.

Jauernig, Othmar. Zivilprozessrecht, 21. ed., München, Beck, 1985

Jhering, Rudolf von. Geist des römischen Rechts auf den verschiedenen Stufen seiner Entwicklung, Teil 2, Abteilung 2, Unveränderter Neudruck der 5. (lezten veränderten) Auflage Leipzig 1898, (lezten veränderten) Auflage Leipzig 1898, ção espanhola de 1910, trad. de Enrique Príncepe y Satorres, Madrid, editorial BaillyBailliere.

Klein, F. Zeit-und Geistesströmungen im Prozess, conferência proferida em Dresden em 1901, in Reden, Vorträge, Aufsätze, Briefe, vol. I, Wien, Manz, 1927.

Lacerda, Galeno. Despacho Saneador, Porto Alegre, La Salle, 1953.

Lebre de Freitas, José. Introdução ao Processo Civil (conceito e princípios gerais à luz do Código revisto), Coimbra, Coimbra ed., 1996

Perelman, Chaïm. Tratado da Argumentação (a nova retórica), em colaboração com Lucie OlberechtsTyteca, 1958, edição brasileira na trad. de Maria Ermantina Galvão G. Pereira, São Paulo, Martins Fontes, 1996.

Perrot, Roger. O processo civil francês na véspera do século XXI, trad. de J. C. Barbosa Moreira, Revista Forense, 342 (abril-maio-junho de 1998):161-168.

Picardi, Nicola. Processo Civile (dir. moderno), in Enciclopedia del Diritto, XXXVI(1987):101-118.

Teixeira de Sousa, Miguel. Estudos sobre o novo processo civil, 2. ed., Lisboa, Lex, 1997
Troller, Alois. Von den Grundlagen des zivil prozessualen Formalismus, Basel, Helbing \& Lichtenhahn, 1945.

. Linfluence de la Constitution Fédérale de la Confédération Suisse sur les droits de parties devant les tribunaux cantonaux en matière de procédure civile, in Cappelletti e Tallon (organizadores), Fundamental guarentees of the parties in civil litigation, Milano, Giuffrè, 1973.
Viehweg, Theodor. Topik und Jurisprudenz (Ein Beitrag zur rechtswissenchaftlichen Grundgenforschung), 5. ed., München, Beck, 1974.

Weber, Max. Economia y sociedad (esbozo de sociología comprensiva), ed. preparada por Johannes Wincklemann, trad. de José Medina Echavarría, Juan Roura Parella, Eugenio Ímaz, Eduardo García Máynez e José Ferrater Mora, México, Fondo de Cultura Económica, 7. reimpressão, 1984. 